\title{
A Study on Release Property through Self Coating in LSR Injection Process
}

\author{
Sang-Gweon Kim, Hyung-Pil Park, Jeong-Won Lee, Yong-Jun Jeon, Baeg-Soon Cha* \\ Heat Treatment R \& D Group, Research Institute of Advanced Manufacturing Technology, KITECH (Korea \\ Institute of Industrial Technology), Incheon, Korea \\ Email: ${ }^{\text {bscha@kitech.re.kr }}$
}

Received 23 June 2015; accepted 28 July 2015; published 31 July 2015

Copyright (C) 2015 by author(s) and Scientific Research Publishing Inc.

This work is licensed under the Creative Commons Attribution International License (CC BY).

http://creativecommons.org/licenses/by/4.0/

(c) $\underset{\mathrm{EY}}{\mathrm{i}}$ Open Access

\section{Abstract}

This study explores the molding processes by using the Multi-component-injection molding (MCM) method, in which monolithic products are molded by attaching mixed liquid-silicone-rubbers (LSRs) to polybutylene terephthalate (PBT) that has the characteristic of self-binding while burning due to Pt catalysts. It is seen that this method increases the binding force between LSR and PBT. The surfaces coated with Polytetrafluoroethylene (PTFE), $\mathrm{Cr}$, Ni, etc. have excellent peeling with plastic and such surfaces are compared with those treated with hot forging die and micro blasting without coating. When peeling tests are performed at the specified polymerization temperature and molding time after LSR molding on these surfaces of hot working die molds without coating, these surfaces show excellent peeling of molds and LSR products. In particular, they show better peeling after micro blasting than surfaces with $\mathrm{Cr}$ and Ni coating as well as surfaces without coating, and the peeling strength also decreases. The results of contact angle and XPS analysis indicate that the LSR binding force is enhanced as an effect of catalysts, though it is not found by SEM. According to the XPS analysis, the structures of the surfaces are close to methyl and vinyl materials that are produced while LSR molding.

\section{Keywords}

Multi-Component-Injection Molding (MCM) Method, Liquid-Silicone-Rubbers (LSRs), Peeling Test, Self Coating, Surface Analysis, Sessile Water Drop Contact Angle Tests

\section{Introduction}

LSRs (liquid silicone rubbers) are polymers that have been applied to various products because they are easy

"Corresponding author.

How to cite this paper: Kim, S.-G., Park, H.-P., Lee, J.-W., Jeon, Y.-J. and Cha, B.-S. (2015) A Study on Release Property through Self Coating in LSR Injection Process. Advances in Materials Physics and Chemistry, 5, 229-243. 
tomold, excellent in chemical resistance, and preserve their physical properties for over 100 years and beyond [1].

LSRs are thermoset elastic materials with vinyl and methyl groups including polydimethyl siloxane (PDMS) and hydrolyzed vinyltrimethoxysilane (VMS) that are silicone polymers. When catalysts with Pt are added to LSRs to harden them during polymerization, they form silicone and oxide binding structures as well as surfaces with hydrophobic methyl groups. These properties help in securing thermal resistance and elasticity of the surfaces coated with LSR. LSRs have been used for insulation of wires and plugs because they are good elastomers excellent in sealing, adhesion, etc.

In particular, it has been applied in the MCM method where thermoset resin LSR is molded on thermoplastic resin material. The LSR injection process is used for producing high quality products because vehicles and electronic devices should satisfy parameters of not only features but structural factors as well.

The MCM method can be easily employed when making various new products, using LSR binding with various polymers depending on the purposes and environment of products. There is, however, an obstacle to making various products in that the binding force of poly silicone binding material is weak compared to general rubbers [2].

Also, the firstly molded thermoplastic products must not be deformed by high temperature of the molds. Thermoplastic resin applied to the MCM molding, therefore, uses materials with high thermal peeling temperature: the typical materials include PC, Polyamide (PA6.6), PEEK, PBT, and polyester resin.

After assessing the required interfacial binding force, materials with chemical affinity are applied to the MCM injection molds that use only thermoplastic resin. As materials with different physical properties are used in the thermoset/thermoplastic MCM injection molding, interactions of two material form new material on the surface of the molds and have an impact on the quality of the products. As such, self-adhesive LSRs are used to enhance interfacial binding force.

Materials added to make MCM are suitable for applying to LSRs due to their strong binding force. However, as this also increases interfacial binding force on the surface of the molds, it causes broken interfacial surfaces and peeling errors. Injected LSRs form covalent bonds or secondary bonds with chemical materials and affect the surface roughness of the molds. Strong binding force between molds and LSRs induces degraded quality of LSR/PBT interfaces while taking out the molds. LSR peel residues on surfaces of molds, in particular, may have an impact on continuous processes. These problems occur due to LSRs that have the characteristic of self-bonding. Various coatings as well as release films and agents are therefore used to enhance peeling on metal surfaces.

In mass production of LSR molds, however, improvement of peeling of molds and products is very important to enhance productivity. While improvement of peeling by lubricant coating on surfaces of molds shows excellent characteristics of surfaces, it has the drawback that it is difficult to guarantee durability and maintenance of coated surfaces. It also limits the formation of uniform layers for complex shapes and raises coating costs of components related to LSR molds.

Therefore, several studies have been conducted to secure peeling without compromising on durability, mass production, and cost effectiveness for LSR product molds with more complicated uses.

On the other hand, there have been various studies on how to enhance the binding force between LSRs and other materials such as thermoplastic resin: many studies propose the induction of new bond structures on the LSR surfaces by activating the surfaces using oxygen or hydrogen plasma. These studies introduce production processes using bonds of poly(dimethlysiloaxne) and vinylgroups, in which the binding force of the major bonds at the terminals of methylsilaxane or polyvinylsilaxane is excellent.

F. Wang reported enhancement in the binding force with corona discharge on surfaces of separate thermoplastic resin, using hydrolyzed vinyltri methyloxy silane(VMS) with $\mathrm{Pt}\left(\mathrm{H}_{2} \mathrm{PtCl}_{6}-6 \mathrm{H}_{2} \mathrm{O}\right)$ halogen material as a surfactant [3].

From the results of studies to enhance binding force in final products of several polymers, improved binding force caused broken products due to degraded peeling on surfaces of molds in the actual mass production, decreasing productivity. This study aimed to improve peeling of LSRs in mass production.

This study analyzed peeling of molds that was caused by the interfacial binding force of LSRs during injection molding of different materials. It was found that the cavity geometry of molds has impacts on the strength of the product interfaces. Binding force was controlled by arranging parameters in this study [4].

In addition, various studies were performed on peeling of injection molding using the roughness of surfaces.

Meanwhile, some researchers have reported problems regarding peeling on the surfaces of molds with $\mathrm{CrN}$, 
TiN, and DLC coatings in the PVD and PACVD processes.

By using molds with $\mathrm{Cr}$ and Ni coating and PTFE coating, that are excellent in peeling, together with micro blasting of surfaces on mold steel (raw material) using particles with high hardness and elasticity, they analyzed surfaces and the peeling strength of products to find the causes of peeling.

The binding force between molds and products was estimated in the ASTM D 3163-01 method and the flexible-to-rigid joint method in which $90^{\circ}$ peel tests were done in the BS 5350:part C10:1976, 1979, etc [5] [6].

On the other hand, it was found that frictional coefficients had impacts on the ejection force in the final ejection stage. This is likely to be related to contact energy on the final surfaces of molds and the interfaces of polymers [7] [8].

In most cases, however, regardless of their properties, coatings have very complex shapes on the surfaces of complicated molds. The surfaces of molds are heated at the burning temperature of Pt surfactants contained in LSR material. To compare peeling in self coating on the molding process of LSRs with that of non-coated molds and molds treated with micro blasting, the binding force between molds and LSRs was measured by peeling strength tests.

According to whether LSR molding was performed on molds or not, changes in surfaces were observed with the field emission scanning electron microscope (FE-SEM). To analyze peeling on surfaces of molds, we measured the angle formed between water drops and their contact surface, using the Sessile water drop contact angle tests, and then surface energy was estimated to check changes in the state of surfaces. To predict the structure of material that affects peeling of the mold surfaces, changes on the mold surfaces while applying LSR molding were analyzed and compared together with changes in the characteristics using X-ray photoelectron spectroscopy (XPS).

By understanding what impacts the adhesive force between LSRs and molds with various coatings has on the peeling of molds by self coating, relations of peeling to changes in the characteristics of the mold surfaces were deduced. When these characteristics are applied to the mass production of LSRs in areas where it is hard to coat due to their complicated shapes, it would secure processes in which the mass production of molds is possible by only arranging the optimal self-binding of LSRs and controlling the burning temperature, even without coating.

\section{Experimental Study}

\subsection{Materials}

The LSR material used in this study was Silopren LSR 2740 TP 3783 of Momentive that enhanced the binding force of LSR products: these LSRs composed of A with Pt catalysts and B, and showed excellent self-bonding when $\mathrm{A}$ and $\mathrm{B}$ were mixed. Further, the two components, the main material and the hardening material, are mixed in a 1:1 ratio.

SKD61 (JIS-standard) material, as shown in Table 1, was selected as the material for molds to estimate peeling when molding LSRs; they were quenched at $1030^{\circ} \mathrm{C}$ and passed through two sessions of tempering heat treatment at $520^{\circ} \mathrm{C}$.

In order that the products are easily released, the top molds for the peeling tests are coated with PTFE that is excellent in peeling. The bottom molds, that determine the shape of products, were fabricated in the dimensions of $100 \times 100 \times 10$, abraded to have a constant roughness, and passed through one of these processes: non-coating, micro blasting (MB), Chromium coating, Nickel coating, and PTFE coating.

\subsection{Ejection Testing}

Figure 1 shows a general injection molding method of manufactured molds: thermoplastic resin was heated and entered into molds in the first molding process.

Figure 2 shows the test method and molds to estimate test specimens. While the bottom molds were ex changed according to each coating method using simple injection molds that were made in the vertical type, tests were

Table 1. Chemical composition of SKD61 Mold Steel (wt\%).

\begin{tabular}{ccccccccc}
\hline Element & C & Si & Mn & P & S & Cr & Mo & V \\
\hline $\begin{array}{c}\text { Percentage } \\
\text { (wt\%) }\end{array}$ & $0.35-0.42$ & $0.80-1.20$ & $0.25-0.50$ & Max.0.030 & Max.0.020 & $4.8-5.5$ & $1.0-1.5$ & $0.8-1.15$ \\
\hline
\end{tabular}




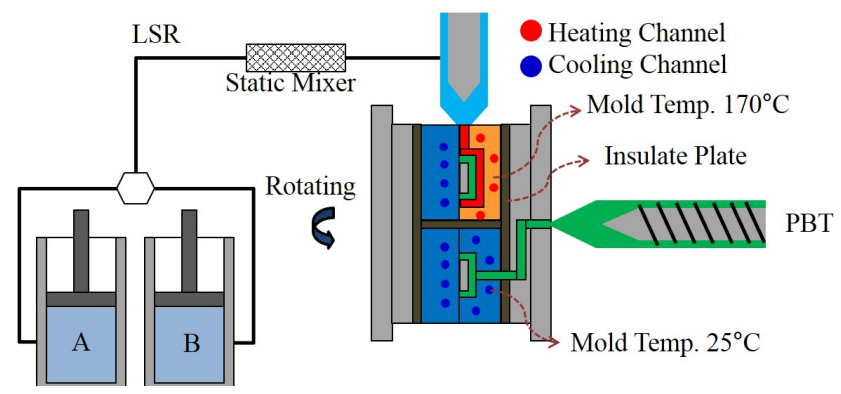

Figure 1. A Diagram of Thermoset Resin (LSR) and Thermoplastic Resin (PBT) Molding by MCM Method.

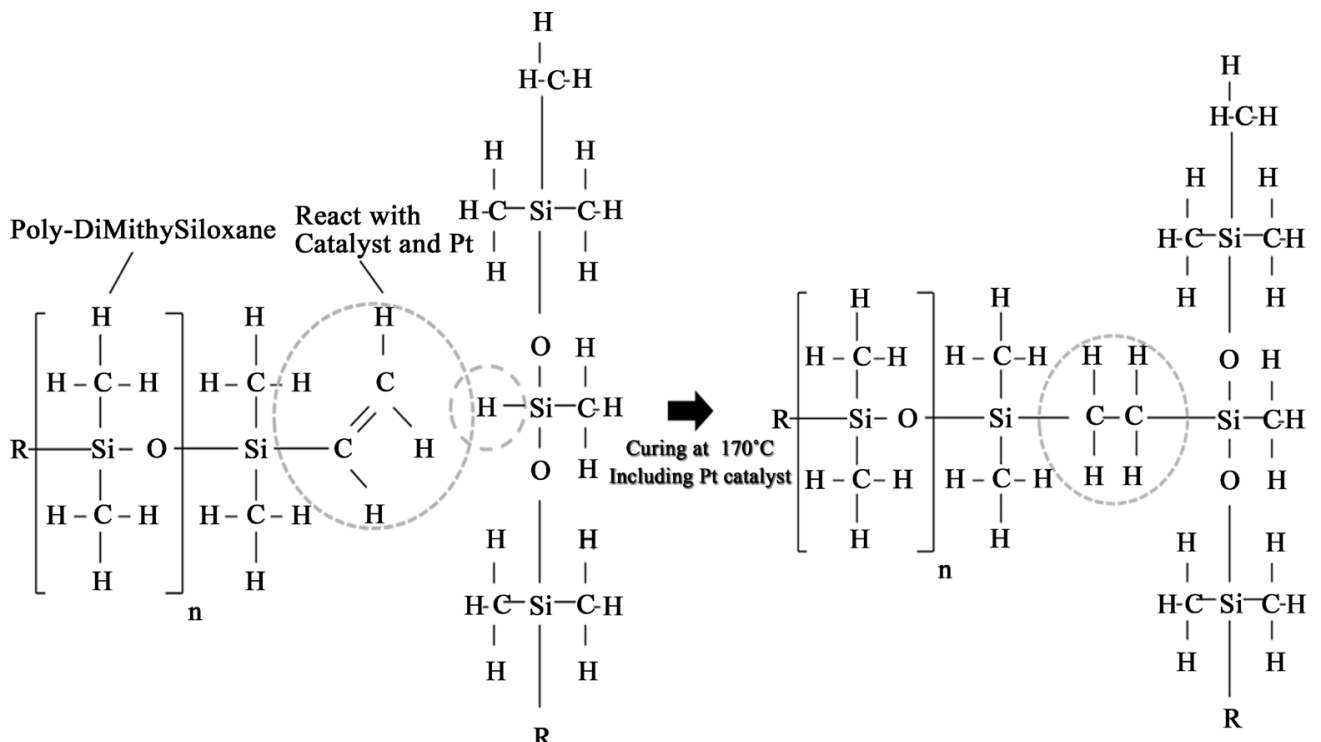

Figure 2. Polymerization of LSRs with a Catalyst.

performed in which the LSR products molded in the constant shape were taken out together with bottom molds.

Resin was injected into the specimens of LSR 2740 for peeling estimation using the carrier plate, and then the top plate compressed resin to the mold specimens while mounting them on the plate. Thermoplastic resin molds were kept at $25^{\circ} \mathrm{C}-100^{\circ} \mathrm{C}$ to be controlled at a constant temperature through heat exchange etc. For the second molding, molds in operation were rotated and silicone was injected into the 1st molded thermoplastic resin. Silicone injected into the hot molds heated by the cartridge heater was added to the final products through hardening.

\subsection{Propagation of Specimen}

The top and bottom plates were treated with fluorine coating to prevent LSR adhesion. To harden LSR 2740, the heating plate mounted with the cartridge heater was heated at $170^{\circ} \mathrm{C}$ as recommended by Mometive according to the physical properties of the material. It was then uniformly hardened for 400 seconds to be perfectly hardened.

\subsection{Measurement of Adhesion Strength}

Samples to compare peeling of molds and LSR molding products were designed to be made as shown in Figure 3(a). Molding products were taken out while being attached on the surface of molds and made in the form of tension tests, as shown in Figure 3(b).

The binding force between molds and products were measured using the flexible-to-rigid joint method, in which the molds and products were fixed by the tension tester to estimate peeling in the same $90^{\circ}$ peel test as in the ASTM D 3163-01 method and BS 5350: part C10: 1976, 1979, etc.: the tension speed was constant at 500 $\mathrm{mm} / \mathrm{min}[6]$.

In the results of peeling tests, the force on interfaces was taken to be the average value in the range of expe- 

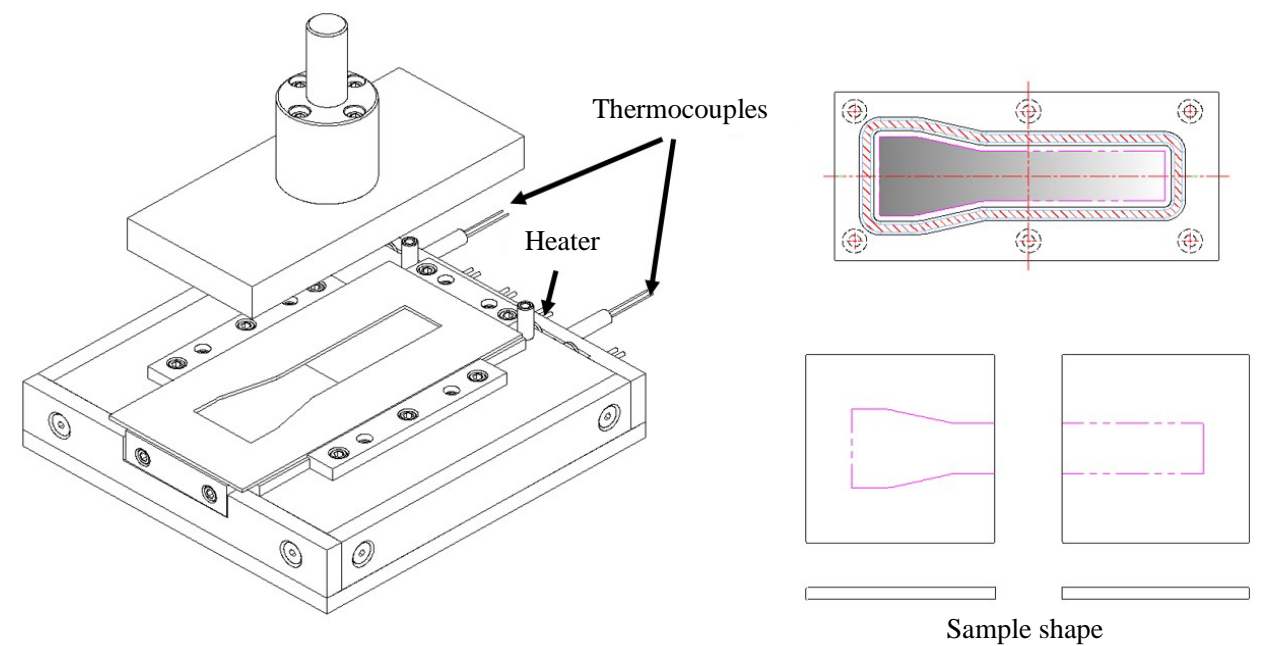

(a)

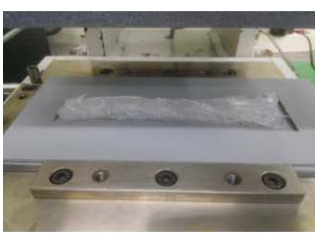

LSR Charge

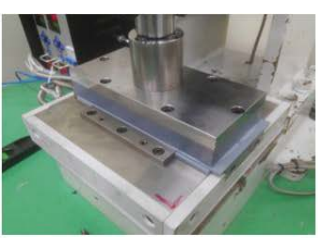

Pressing \& Curing

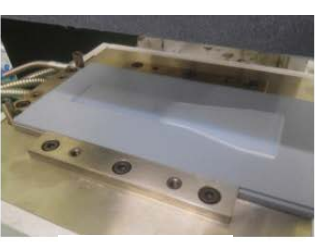

De-molding

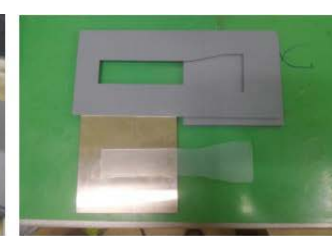

Separation of test specimen

(b)

Figure 3. Mold Coating Specimens and the Manufacturing Process of Specimens for Peeling Estimation of LSR 2740. (a) Peeling test Jig; (b) Procedure for molding of peeling test specimen.

riments for quantitative analysis, and W-peeling force was calculated by average force (F) and the width (b) of interfaces. Figure 4 shows the experimental instrument and typical measurement data.

\subsection{Characterization}

Due to additives used to enhance adhesion with plastic, applied DSRs also enhance adhesion of the surface of molds. This is disadvantageous for the peeling of molds and plastic resin. To improve the performance of DSRs, there have been many studies on coating technology with various peeling.

LSR residue and its components were analyzed by SEM and EDS (JEOL FE-SEM/EDS, JSM-7001F) measurement on the surface of LSR molds as well as specimens passed through these treatments: non-coating, chromium, nickel, PTFE coating, and micro blasting.

To observe changes on the surfaces by LSRs, the shape of the surfaces was observed by AFM (Nano-R AFM, Pacific Nano technology). At 10 seconds after water drops made a thermodynamic equilibrium in the Sessile water drop method (DSA30, Kruss), the contact angle on the surface of the bottom mold according to coating methods was measured: it measured the angle that the contact point on the surface of the solid made with the end point of the liquid drop curve at the contact point of solid-liquid-gas [6].

\section{Results and Discussion}

\subsection{Effects of Coating}

Results of peeling experiments on various LSR mold coating specimens were shown as in Figure 5(a). The average adhesion force and the load until release by peeling after reaching the constant load, was calculated as shown in Figure 5(b).

In Figure 5(b), the average value of the peeling strength was the maximum for LSR 2740 and PBT specimens; and the average adhesion force was $0.27 \mathrm{kgf} / \mathrm{mm}$.

The LSR products of PTFE coating specimens were peeled right after molding due to their excellent peeling 

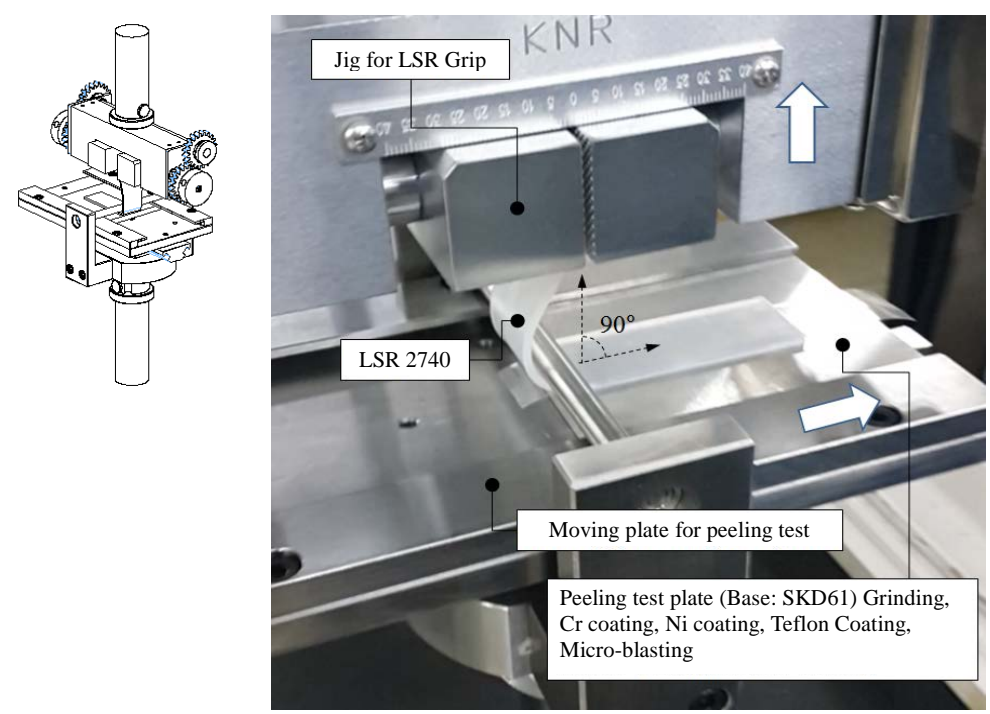

(a)

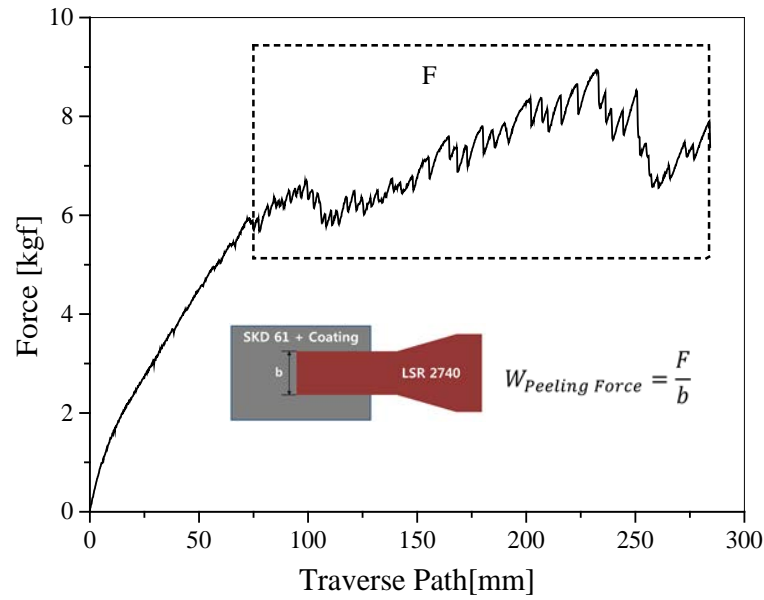

(b)

Figure 4. Instrument for peeling estimation and its results. (a) Peeling strength test; (b) Result of strength estimation.

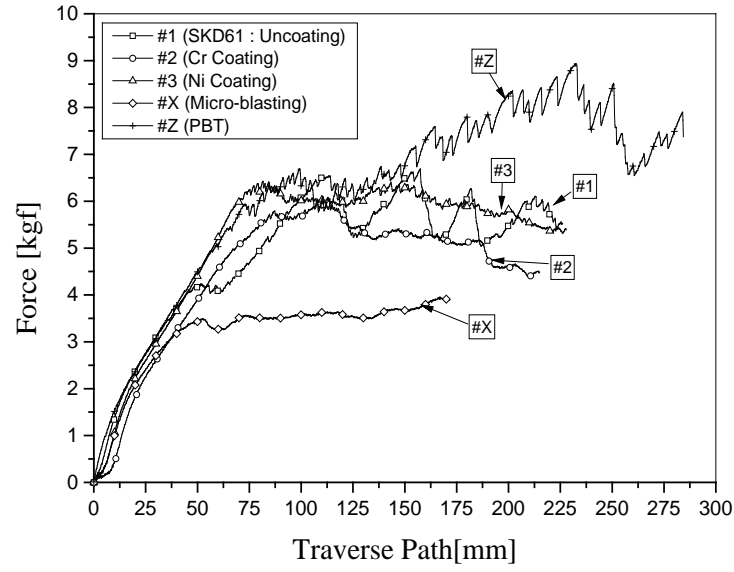

(a)

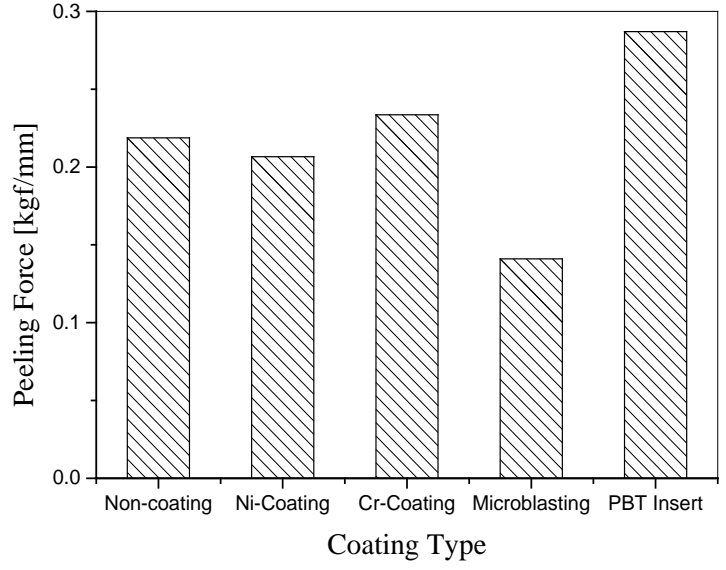

(b)

Figure 5. Results of estimating peeling strength according to types of coating. (a) Results of estimating peel force; (b) The average peel strength at constant load. 
top mold like characteristic. For this reason, their adhesive specimens could not be made and they were excluded in the peeling experiment.

The average adhesive force of SKD61 abraded specimens and those with $\mathrm{Cr}$ and $\mathrm{Ni}$ coating was $0.21-0.23$ $\mathrm{kgf} / \mathrm{mm}$. As this value was not largely different from the peel strength of PBT, it would have impacts on LSR/PBT interfaces compared to peeling from molds and LSR products.

The average adhesive force of micro blasting specimens without coating was $0.14 \mathrm{kgf} / \mathrm{mm}$; and their peel strength showed the lowest values among estimated specimens. This result showed that peeling could be obtained through mechanical surface treatment without chemical coating except for PTFE coating.

Results of observation on surfaces and cross sections with SEM according to types of coatings are shown in Figures 6(a)-(e): it is difficult to find formation of layers in the cross sections though the brightness depends on the surfaces after burning.

Meanwhile, the adhesive force between the LSR surfaces and molds was observed on surfaces formed through

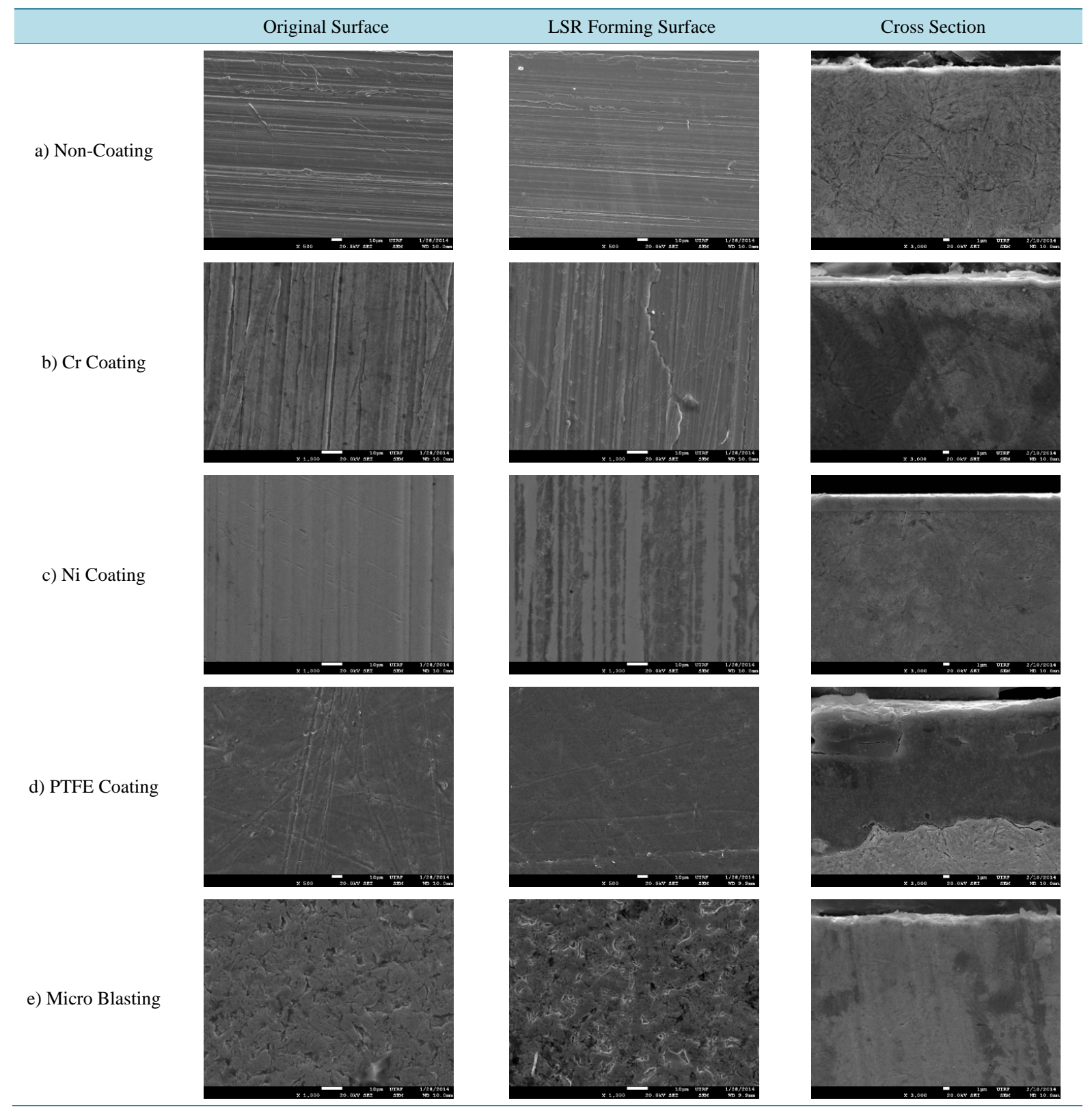

Figure 6. States of surface treatment of molds with several coatings, and surfaces and cross sections after LSR molding. 
micro blasting as shown in Figure 6(e), considering that it would be affected by the adhesion area and enhanced adhesive force due to expanded volume caused by LSR molding pressure and hardening reactions.

The phenomenon of LSRs forming self-binding components attached to molds could be caused by the chemical reactions that occurred at points where LSRs contacted surfaces of molds while molding. The changes caused by chemical reactions on the surfaces of LSRs before and after molding were compared according to types of coatings on surfaces, as shown in Figure 7, using changes in the water contact angle with LSR molded surfaces and unmolded surfaces for various coating specimens.

\subsection{Microscopic Analysis and Characteristics of Coating Surfaces}

In the cases when LSR molding was performed once, as shown in Figure 5(a), components of surfaces for the molds showed almost no difference between LSRs and molds.

In the molds with LSR molding performed more than four times, however, the ratio of particular atoms on the surfaces increases as shown in Table 2. As for the ratio of components for non-coated samples, micro blasting, and PTFE coating layers, it increased in these ranges: carbon increased from 24.12 at $\%$ to 30.42 at $\%$ for non-coating; 4.5 at\% to 7.21 at\% for oxide; and 1.46 at\% to 2.4 at $\%$ for silicone .

In the molds with micro blasting, on the other hand, carbon showed a small increase from 31.87 at $\%$ to 32.02 at $\%$ after five times of LSR molding tests. For oxide, it increased from 19.69 at $\%$ to 23.50 at\%: it showed a substantially higher ratio than abraded molds. For silicone, it increased nearly two times from 1.85 at\% to 3.96 at\%. This was caused by due to an increase of oxide on surfaces for micro blasting, was proportional to the roughness, and silicone elements are more absorbed at LSRs.

The Sessile water drop method that was performed to predict the state of surfaces shows a surface contact angle of $86.8^{\circ}$ for SKD61 in Figure 7.This value is close to hydrophilic; but it changed to $114.4^{\circ}$ after LSR molding, indicating hydrophobic tendencies.

When chromium coating was done for SKD61, the contact angle was $97.4^{\circ}$ at coating as shown in Figure 7; and it increased to $120.6^{\circ}$ after LSR molding as shown in Figure 8.

When nickel coating was done for SKD61, the contact angle at coating was $82.9^{\circ}$ as shown in Figure 7; and it increased to $112.1^{\circ}$ on the surface of LSR molding, which is a little lower than contact angles for chromium coating and non-coating. It is assumed that the material formed by reactions on the surface and change in the roughness had impacts on the peeling of products.

When PTFE coating was done for SKD61, the contact angle on the surface was $74.8^{\circ}$, which is hydrophilic; and it changed to $117.7^{\circ}$ on the surface of LSR molding.

After LSR molding, the contact angle increased by $2^{\circ}-5^{\circ}$ on the PTFE coated surfaces that had excellent peeling. When the contact angle was measured on the surfaces of LSR products after molding as shown in Figure 9, it showed large differences in the angle on the mold surfaces: this means that LSR products have excellent hydrophobic properties. Structures formed during the LSR molding process were found on the surfaces of

Table 2. LSR: Results of EDS Component Analysis on the Surfaces of Molds with 5 Times Repeated LSR Molding.

\begin{tabular}{|c|c|c|c|c|c|c|}
\hline & \multicolumn{2}{|c|}{ SKD61 } & \multicolumn{2}{|c|}{ PTFE } & \multicolumn{2}{|c|}{ Micro Blasting } \\
\hline & Mold Surface & LSR Molding & Mold Surface & LSR Molding & Mold Surface & LSR Molding \\
\hline $\mathrm{C}$ & 24.12 & 30.42 & 28.45 & 28.25 & 31.87 & 32.02 \\
\hline $\mathrm{O}$ & 4.5 & 7.21 & 0.54 & 0.55 & 19.69 & 23.50 \\
\hline $\mathrm{F}$ & 2.74 & 4.84 & 70.61 & 70.80 & 2.25 & 2.37 \\
\hline $\mathrm{Si}$ & 1.46 & 2.40 & 0 & 0 & 1.85 & 3.96 \\
\hline $\mathrm{V}$ & 0.65 & 0.51 & 0 & 0 & 0.48 & 0.43 \\
\hline $\mathrm{Cr}$ & 4.03 & 3.21 & 0 & 0 & 2.49 & 2.14 \\
\hline Mn & 0.00 & 0.30 & 0 & 0 & 0.26 & 0.19 \\
\hline $\mathrm{Fe}$ & 61.96 & 50.55 & 0.11 & 0.12 & 40.71 & 35.01 \\
\hline $\mathrm{Ni}$ & 0 & 0 & 0 & 0 & 0 & 0 \\
\hline Mo L & 0.54 & 0.57 & 0.29 & 0.27 & 0.40 & 0.37 \\
\hline
\end{tabular}




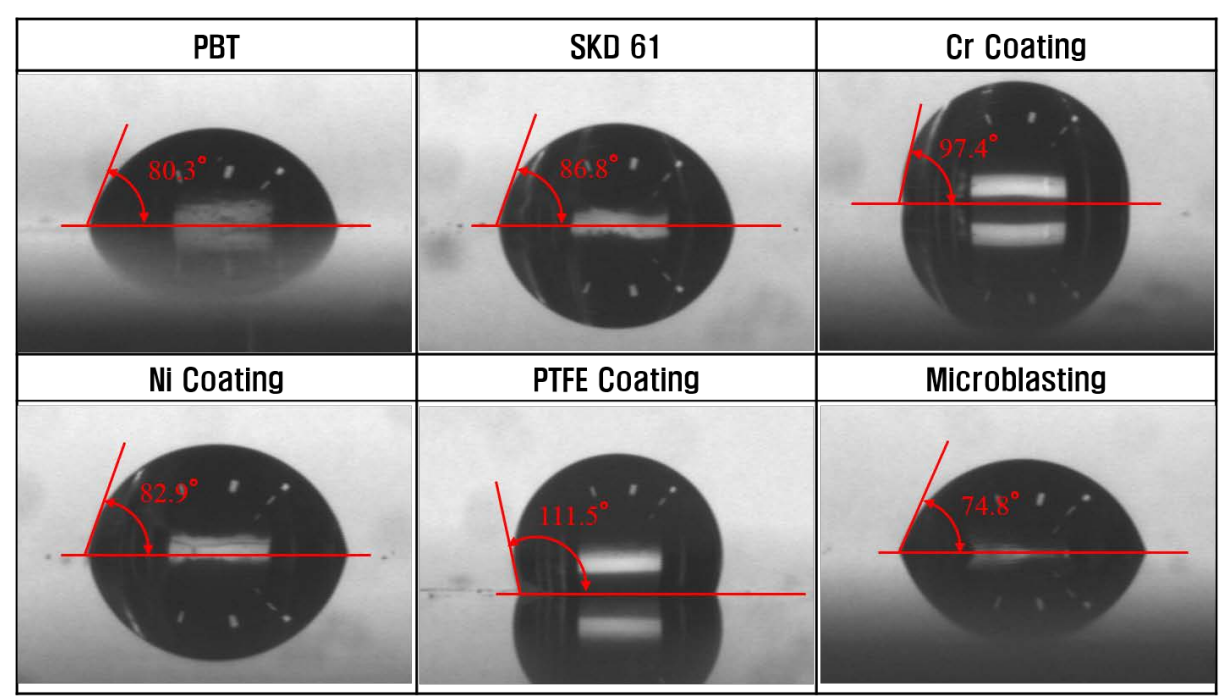

Figure 7. Contact angles measured on the surfaces of molds before LSR burning.

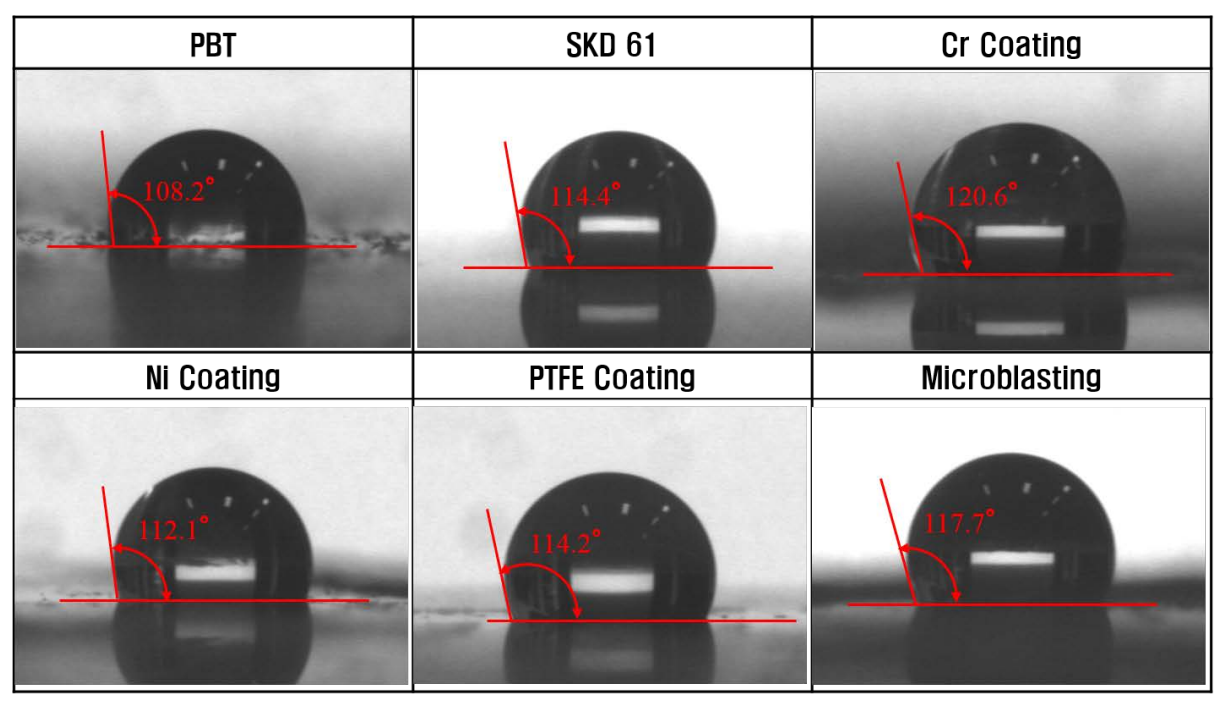

Figure 8. Water contact angles measured on the surfaces of molds after LSR molding.
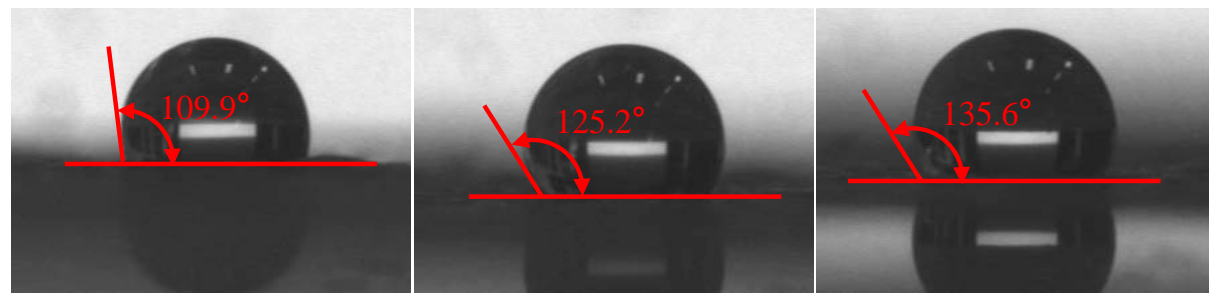

Figure 9. Measurement of the water contact angles of silicone.

all metal materials including PTFE.

\subsection{Analysis of the Characteristics of Repeated Molding}

LSR molds are parts manufactured by mass production and cannot secure durability of their coated surfaces by general coating. Coating costs of component parts related to LSR molding have therefore increased.

For PTFE coating with excellent lubricity, coating may be difficult due to the complex shapes of precise 
components or parts that require precise dimensions. For these components or parts, it is necessary to study surface treatment methods.

In this study, LSR material with excellent self-binding was selected and surfaces and components were analyzed for specimens that have similar characteristics to LSR products. As a result, residue coating layers were formed on the surfaces of coating specimens after LSR coating. This means that any shape of LSR layer can form on the surfaces of LSR coating.

In this study, therefore, LSR coating was repeated 25 times for SKD61 abraded specimen and micro blasting specimen without coating in consideration of durability, mass production, and cost reduction of LSR molds, and then changes in adhesive force and water contact angle were analyzed. Figure 10 shows measured peeling strength and calculated adhesive force after repeated LSR molding for these specimens: a) SKD61 + non-coated specimen, and b) SKD61 + micro blasting specimen.

As shown in Figure 10(a) and Figure 10(b), the peeling strength for the two specimens was large for LSR molding once; but it showed lower value up to $1 \mathrm{~kg}$ as the repeated times of LSR molding increased. The decrease in the peeling strength in Figure 10(b) was more than seen in Figure 10(a); there was also a difference in the contact angle up to $5^{\circ}$, showing a change to the hydrophobic region in Figure 10(c) and Figure 10(d).

To compare the differences and their effects on surfaces with abraded SKD61, micro blasting, and PTFE coating, the surfaces were analyzed through AFM. Figure 11 shows reports the state of the surfaces. The average roughness on the surfaces with LSR molding once for non-coated SKD61 was $0.042 \mu \mathrm{m}$ as the Ra value and $0.234 \mu \mathrm{m}$ as the roughness value, as shown in Figure 11(a).

In the case of SKD61 with LSR molding repeated five times for various levels of roughness of molds or other

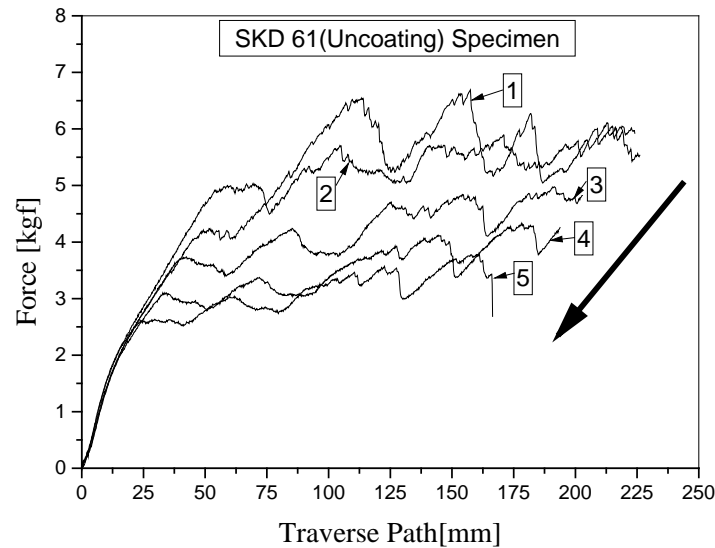

(a)

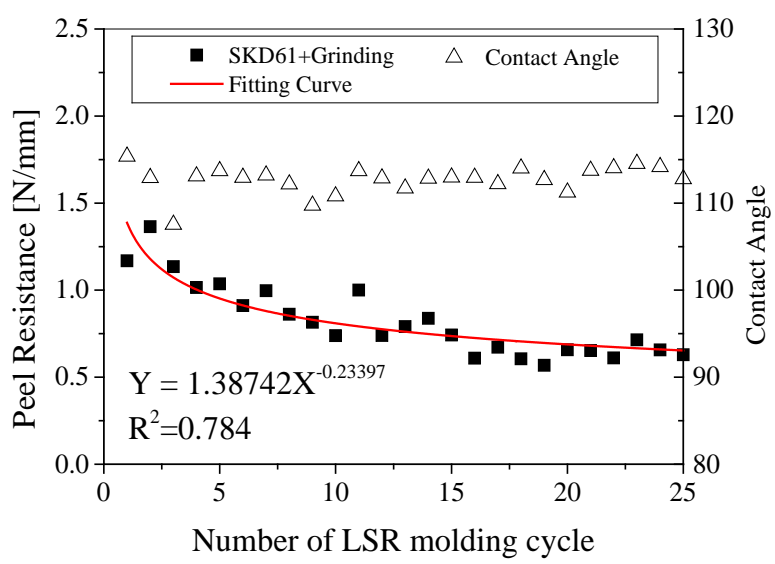

(c)

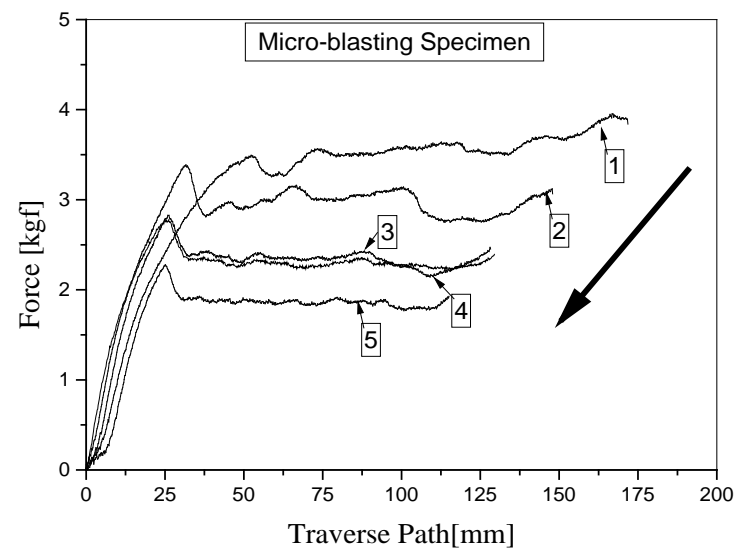

(b)

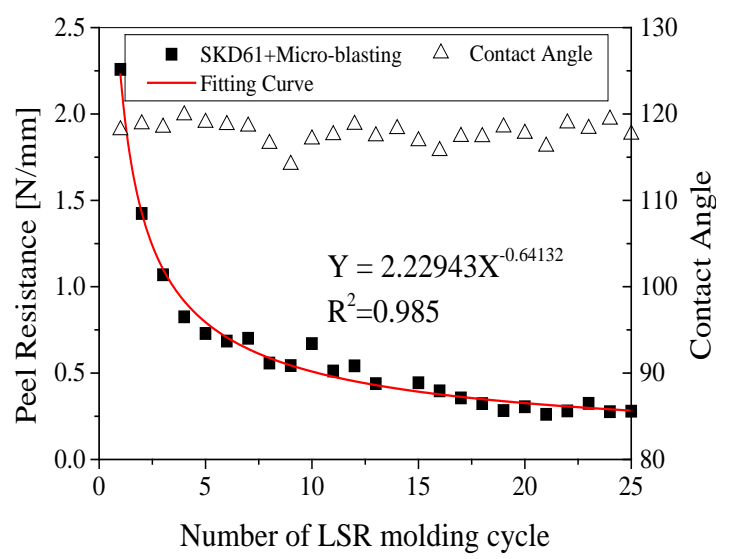

(d)

Figure 10. Changes in load and sessile contact angle during LSR repeated molding. (a) Peeling strength of non-coated specimen; (b) Peeling strength micro blasting treated specimen; (c) Contact angle on non-coated specimen; (d) Contact angle on micro blasting treated specimen. 


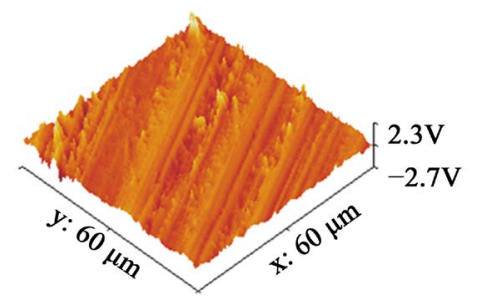

(a)

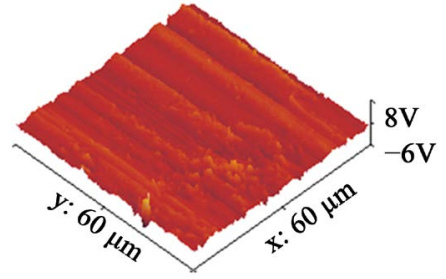

(b)

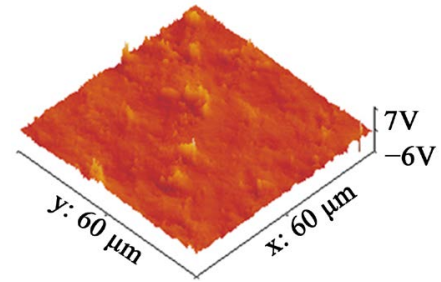

(c)

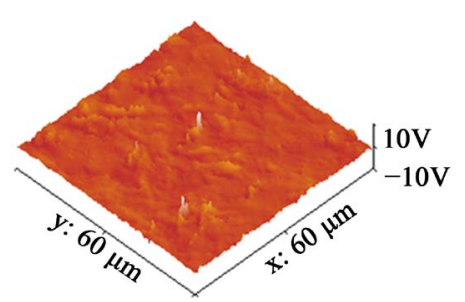

(d)

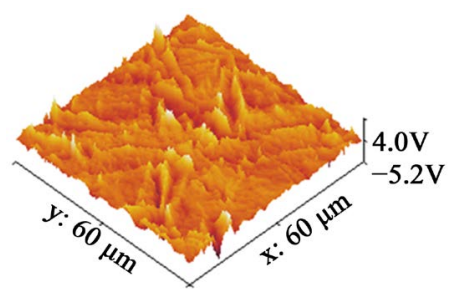

(e)

Figure 11. Roughness of Main Products with AFM. (a) SKD61 performed once; (b) SKD61 performed 5 times; (c) MB performed once; (d) MB repeated 5 times; (e) PTFE.

surface properties, a decrease in binding force was observed as the treated times increases; the average roughness was $0.32 \mu \mathrm{m}$ as the Ra value and $1.5 \mu \mathrm{m}$ as the Rz value, as shown in Figure 11(b): the roughness rather increased. The average roughness was analyzed with AFM on the surfaces with LSR molding once after micro basting, as shown in Figure 11(c): we obtained $0.12 \mu \mathrm{m}$ as the Ra value, $0.54 \mu \mathrm{m}$ as the Rz value. On the surfaces with LSR molding five times after micro basting, as shown in Figure 11(d), the average roughness was $0.14 \mu \mathrm{m}$ as the Ra value and $0.77 \mu \mathrm{m}$ as the Rz value.

As the result of AFM observation on PTFE coated surfaces on molds, as shown in Figure 11(e), the Ra value was $0.138-0.241 \mu \mathrm{m}$ and the $\mathrm{Rz}$ value was $0.73-1.315 \mu \mathrm{m}$.

As shown in Figure 11(a) and Figure 11(b) as well as Figure 11(c) and Figure 11(d), Ra and Rz (the average roughness and the maximum average roughness) increased as the number of LSR molding sessions increased.

\subsection{Results of Analysis According to the State of Binding Energy with XPS}

The specimen of the bottom mold was etched for 10 minutes after performing LSR molding once and again after LSR molding repeated 5 times, and the foreign material was removed. Next, the binding energy was measured with the XPS device [1].

Figure 12 shows the results of observation on binding structures of Si 2p and C1s on the surfaces after performing LSR molding once on SKD61 abraded molds without coating. The results of observation of the state of energy in each atom via curve fitting, as shown in Figure 12(a), indicate that $\mathrm{SiO}_{3}-\mathrm{C}(102.8 \mathrm{eV})$ occupied almost all the silicone structures before etching (i.e., in the outer part of molds). These structures were similar to components of repeated structures of LSRs. As shown in Figure 12(c), $\mathrm{SiO}_{3}-\mathrm{C}(102.8 \mathrm{eV})$ and $\mathrm{SiO}_{2}-\mathrm{C}_{2}(101.6$ $\mathrm{eV}$ ) occupied almost $50 \%$ of surfaces after etching. Investigating the C1s binding structures in Figure 12(b), the outer surfaces had C-C/C-H (284.6 eV), C-Si $(283.4 \mathrm{eV})$, and C-O $(285.4 \mathrm{eV})$ structures: external binding of methyland vinyl groups, the major structures of LSRs, showed a mixed form with oxide. After C1s etching, the surfaces were composed of bonds in which most were methyl groups, C-C/C-H.

The distribution of binding energy on the surface of SKD61 LSR molding repeated 5 times shown in Figure 13 indicates that most of the surface was occupied with $\mathrm{SiO}_{3}-\mathrm{C}(102.8 \mathrm{eV})$ as shown in Figure 12(a), but $\mathrm{SiO}_{-} \mathrm{C}_{3}(100.4 \mathrm{eV})$ remarkably increased as shown in Figure 13(a). Further, C-C/C-H $(284.6 \mathrm{eV})$ in the C1s structure occupied most of the surface before etching, as shown in Figure 13(b). $\mathrm{SiO}_{3}-\mathrm{C}(102.8 \mathrm{eV})$ in the $\mathrm{Si} 2 \mathrm{p}$ binding structure after etching was more dominant than $\mathrm{SiO}_{2}-\mathrm{C}_{2}(101.6 \mathrm{eV})$, as shown in Figure 13(c). Figure 13(d) showed the same structure as in Figure 13(b).

Figure 14 shows the results of binding energy on the surfaces of molds with SKD61 micro-blasting LSR molding performed once. Figure 14(a) shows the $\mathrm{Si} 2 \mathrm{p}$ structure that was occupied largely by $\mathrm{SiO}_{3}-\mathrm{C}(102.8 \mathrm{eV})$ 


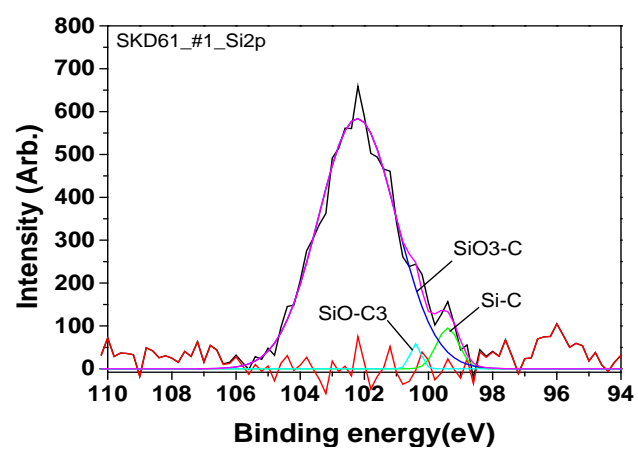

(a)

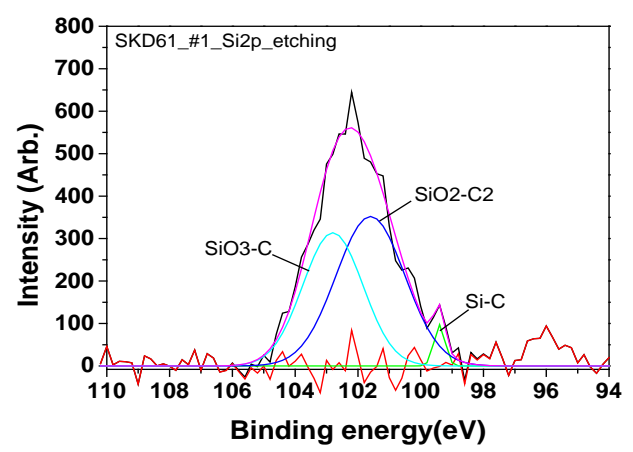

(c)

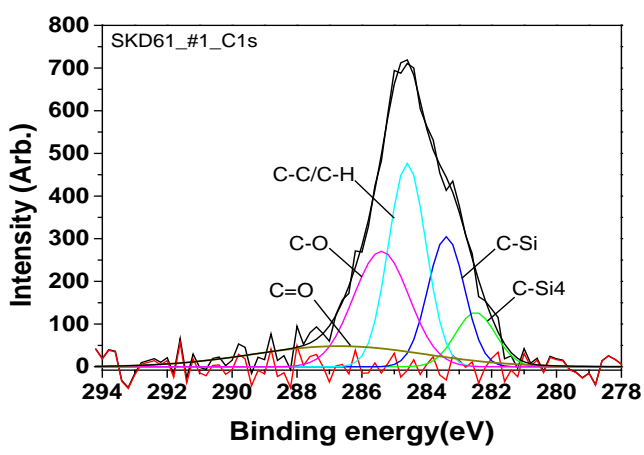

(b)

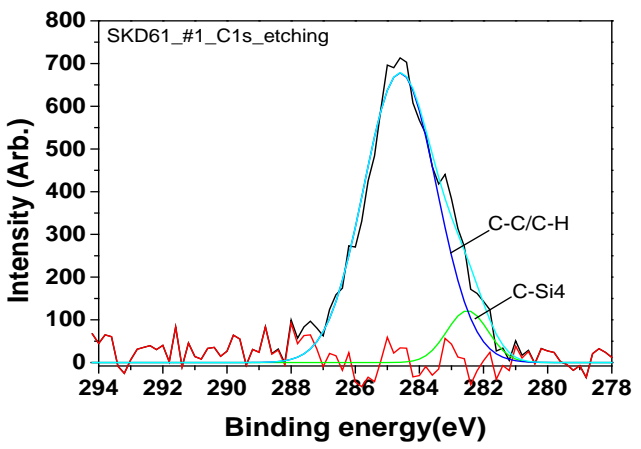

(d)

Figure 12. Results of Analysis on XPS Surface Structures after Performing LSR Molding Once on Non-coated Molds. (a) Si 2p as-coated; (b) C1s as-coated; (c) Si 2p etched; (d) C1s etched.

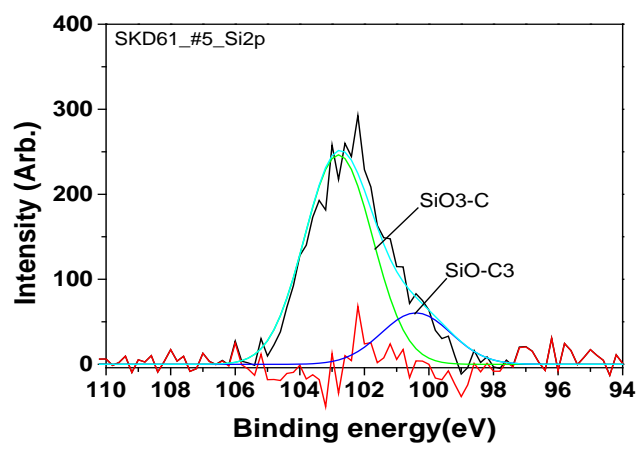

(a)

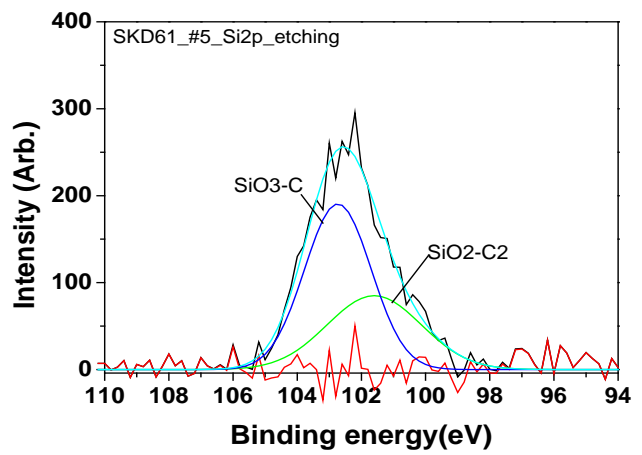

(c)

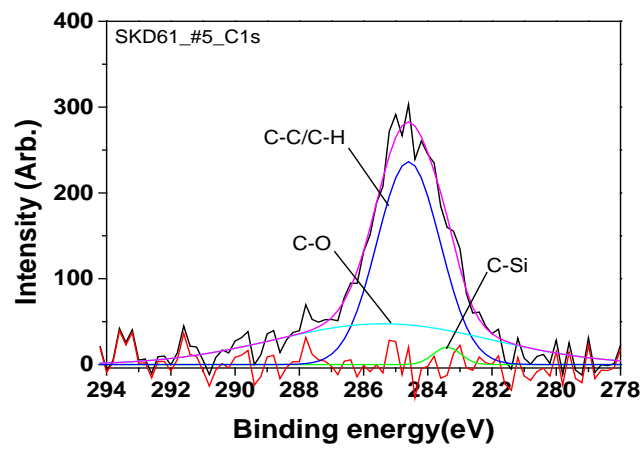

(b)

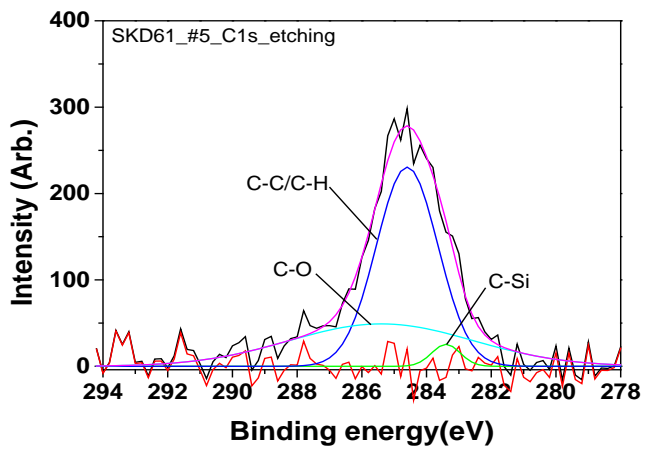

(d)

Figure 13. Results of Analysis on XPS Surface Structures after LSR Molding Performed 5 times on Non-coated Molds. (a) Si 2p as-coated; (b) C1s as-coated; (c) Si 2p etched; (d) C1s etched. 


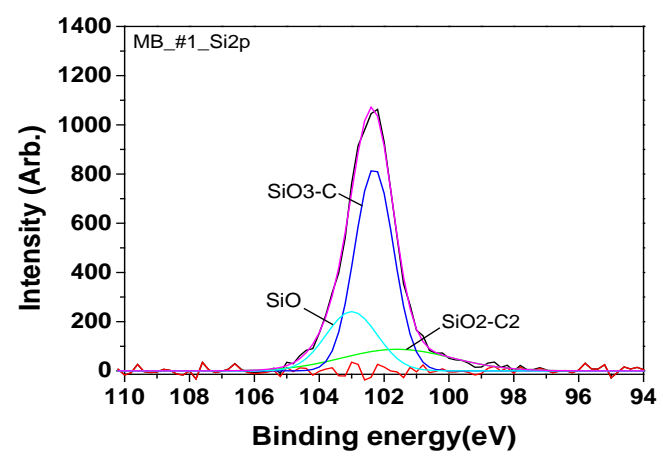

(a)

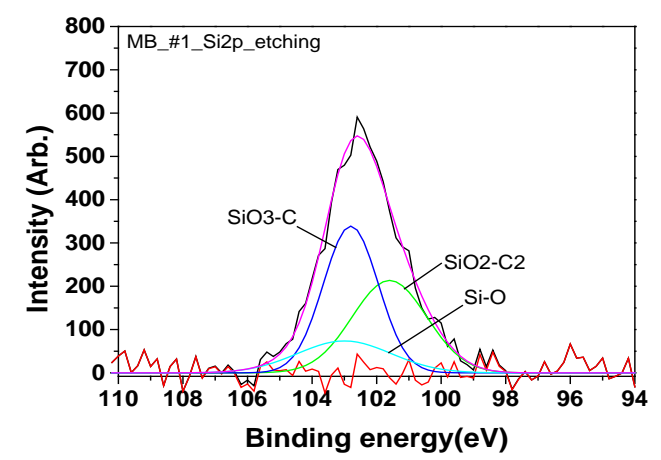

(c)

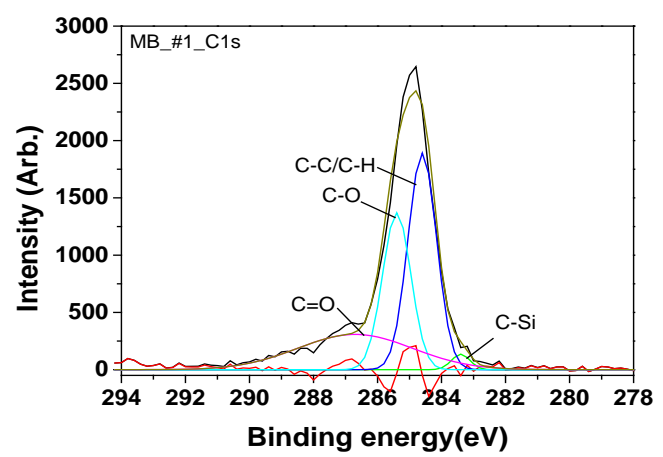

(b)

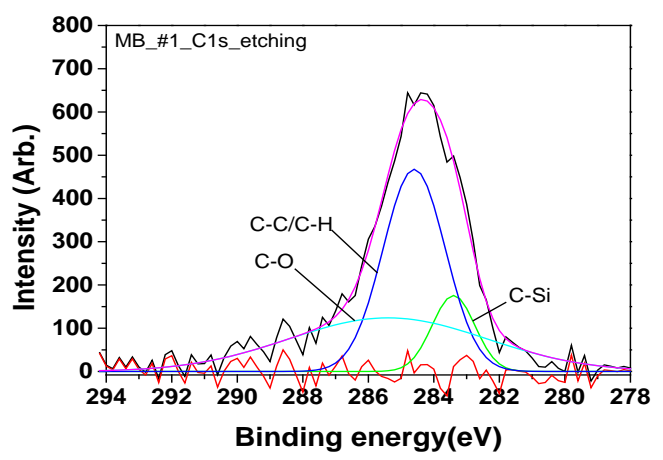

(d)

Figure 14. Results of Analysis on XPS Surface Structures after one-time LSR Molding of Micro Blasting Molds. (a) Si 2p as-coated; (b) C1s as-coated; (c) Si 2p etched; (d) C1s etched.

and Si-O (103.0 eV); the C1s structure was occupied with C-C/C-H (284.6 eV) and a large amount of C-O (285.4 eV), and the binding strength was very strong, as shown in Figure 14(b). After etching, $\mathrm{SiO}_{3}-\mathrm{C}(102.8$ $\mathrm{eV})$ and $\mathrm{SiO}_{2}-\mathrm{C}_{2}(101.6 \mathrm{eV})$ caused an increase in the Si 2p energy as shown in Figure 14(c); and the C-C/C-H bonds were dominant in Figure 14(d).

Figure 15 shows the results of binding energy on the surfaces of molds with SKD61 micro-blasting LSR molding performed 5 times. The $\mathrm{Si} 2 \mathrm{p}$ structure as shown in Figure 15(a) was occupied with $\mathrm{SiO}_{3}-\mathrm{C}(102.8 \mathrm{eV})$, Si-O $(103.0 \mathrm{eV})$, and $\mathrm{SiO}_{2}-\mathrm{C}_{2}(101.6 \mathrm{eV})$, in which the $\mathrm{Si}-\mathrm{O}(103 \mathrm{eV})$ and $\mathrm{SiO}_{2}-\mathrm{C}_{2}(101.6 \mathrm{eV})$ remarkably increased compared to the case shown in Figure 14(a). It is speculated that silicone structures were easily absorbed as a large amount of oxide was formed on the mold surfaces due to micro blasting. The C1s structure was largely occupied with C-C/C-H (284.6 eV) as seen in Figure 15(b). After etching, only Si-O (102.8 eV) was dominant and $\mathrm{SiO}_{2}-\mathrm{C}_{2}(101.6 \mathrm{eV})$ increased in the $\mathrm{Si} 2 \mathrm{p}$ energy, as shown in Figure 15(c).

Figure 15(d) shows bonds composed of C-C/C-H and C-O, C-Si. It is assumed that these structures form sufficient bonds with large amounts of oxide on the surfaces of micro blasting molds with LSR molding performed 5 times, compared to those with LSR molding performed once, and the major structures of LSRs made layers. The same results could be predicted from the fact that there were differences in the amount of carbon and the ratio of major components on the surfaces of non-coated mold steel and those with micro blasting, from the results of EDS surface analysis on the mold surfaces with LSR molding performed 5 times.

Figure 16 shows the results of surface analysis of PTFE coated molds with LSR molding performed 5 times. Figure 16(a) shows the Si 2p structures that were composed of $\mathrm{SiO}_{2}-\mathrm{C}_{2}(101.6 \mathrm{eV}), \mathrm{SiO}-\mathrm{C}_{3}(100.4 \mathrm{eV})$, and $\mathrm{SiO}_{3}-\mathrm{C}(102.8 \mathrm{eV})$. Figure 16(b) shows that C-Si $(283.4 \mathrm{eV})$ structures were more dominant than C-C/C-H, $\mathrm{C}-\mathrm{O}$ structures. This was very different from the surface structures of non-coated and micro blasting molds: it means that these structures have bonds with optimal structures to enhance peeling.

In other words, these oxide structures are stable in the Si bonds, and the $\mathrm{C}$ structures with micro blasting have more C-C/C-H than C-Si. In the cases of PTFE coating, C-Si structures are remarkably dominant than C-C/C-H and should form stable films on surfaces to decrease reactions with LSRs; and peeling is excellent even though the contact angle is less than $120^{\circ}$. 


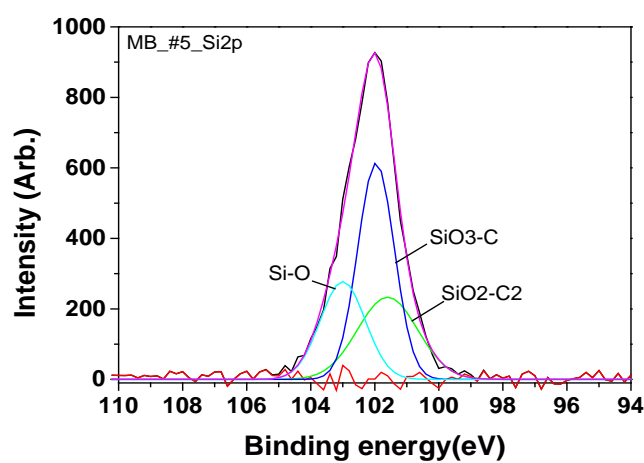

(a)

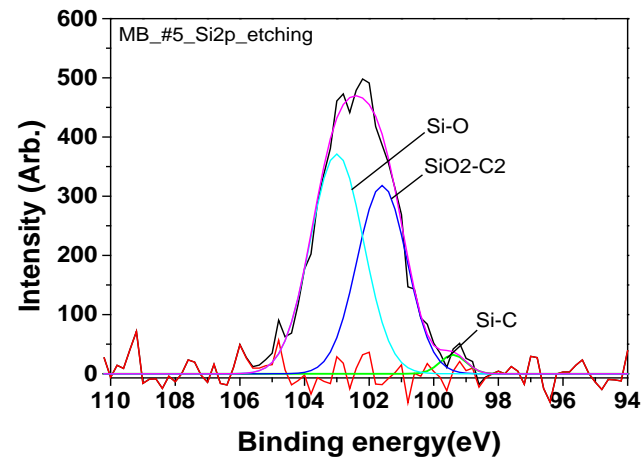

(c)

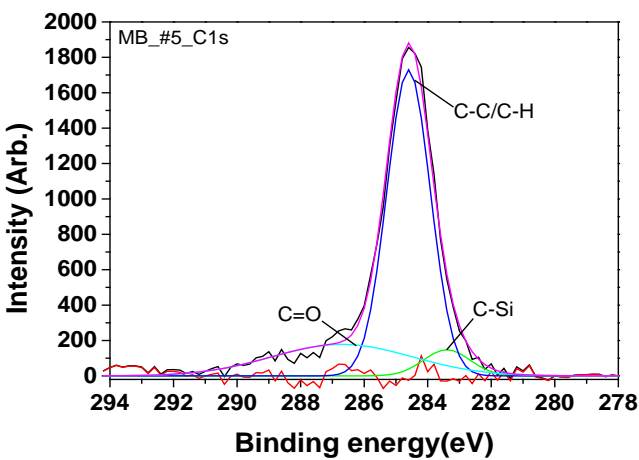

(b)

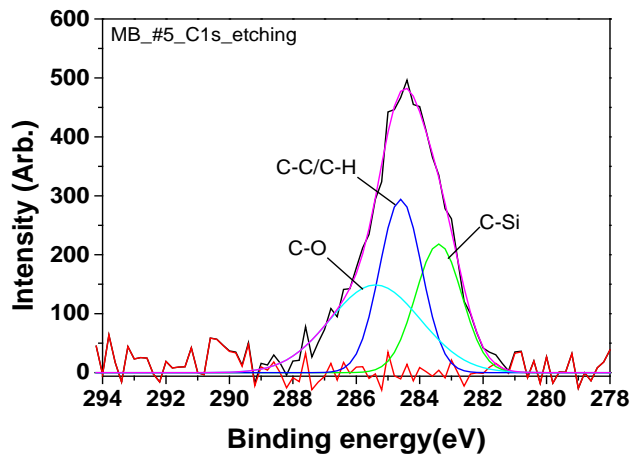

(d)

Figure 15. Results of Analysis on XPS Surface Structures after LSR Molding Repeated 5 Times of Micro Blasting Molds. (a) Si 2p as-coated; (b) C1s as-coated; (c) Si 2p etched; (d) C1s etched.

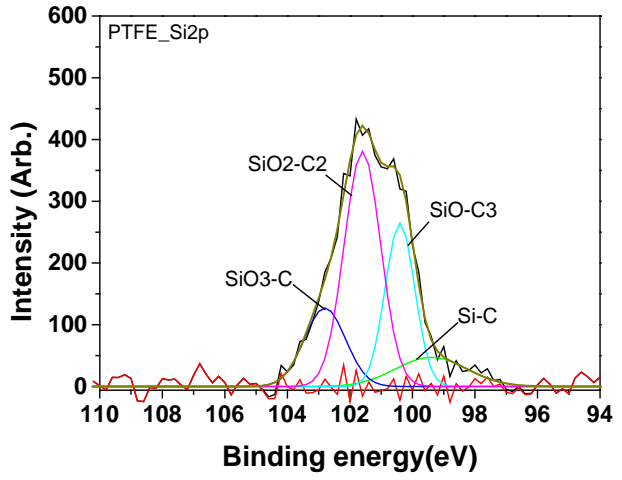

(a)

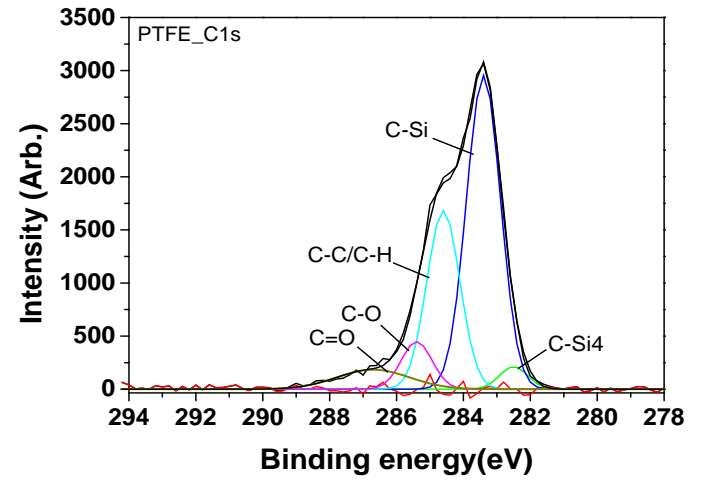

(b)

Figure 16. Results of Analysis on XPS Surface Structures after five-time LSR Molding of PTFE Coating Molds. (a) Si 2p; (b) C1s.

\section{Conclusions}

1) In this study for the development of products with LSR material, the simultaneous forming and molding method of structures with thermoplastic resin was applied to the MCM process using mixed 2740 material and self-binding material added with a Pt catalyst.

2) The study discussed peeling problems with molds and products, caused by the material added to enhance the peeling strength. To estimate enhanced peeling by coating, surface treatments such as $\mathrm{Cr}$, Ni, PTFE, and micro blasting were performed.

3) In particular, as there was a problem with PTFE due to its tendency to form a width of tens of microns, micro blasting instead of coating treatment was conducted for LSR injection and molding. After repeating this 
process several tens of times, it was found that the peel strength greatly decreased.

4) These phenomena could be analyzed with EDS and XPS, because it promoted the molding of LSR material and various chemical reactions on metal and oxide surfaces of metal material with the aid of Pt catalysts entered to enhance self-binding, and formed layers on the outer surfaces.

5) Results of contact angle measurement by Sessile water drop test as well as XPS surface analysis showed that LSR products were hydrophobic. As results of surface analysis after performing LSR molding several times, binding structures similar to LSRs were formed between molds and LSRs by silicone and methyl and vinyl chemicals via self coating. Bonds were differently formed according to the states of the outer surfaces: non-coated molds, micro blasting molds, and PTFE molds. The peeling strength was also different according to the types of bonds.

6) Therefore, it was proposed that PTFE coating with excellent peeling should be applied to major surfaces using micro blasting to precisely fabricate parts in instances where PTFE coating was difficult to be applied.

\section{References}

[1] Siahkali, A.G., Mitra, S., Kingshott, P., Almdal, K., Bloch, C. and Rehmeier, H.-K. (2005) Investigation of the Hydrothermal Stability of Cross-Linked Liquid Silicone Rubber (LSR). Polymer Degradation and Stability, 90, 471-480. http://dx.doi.org/10.1016/j.polymdegradstab.2005.04.016

[2] Kühr, C., Spörrerand, A. and Altstädt, V. (2013) Determination of Adhesion between Thermoplastic and Liquid Silicone Rubbers in Hard-Soft-Combinations via Mechanical Peeling Test. Proceedings of the Polymer Processing Society 29th Annual Meeting, Nuremberg, 15-19 July 2013, S04-poster.

[3] Wang, F., Li, Y.N. and Wang, D. (2013) Adhesion Enhancement for Liquid Silicone Rubber and Different Surface by Organosilane and Pt Catalyst at Room Temperature. Bulletin of Materials Science, 36, 1013-1017. http://dx.doi.org/10.1007/s12034-013-0575-8

[4] Roth, J., Albrecht, V., Nitschke, M., Bellmann, C., Simon, F., Zschoche, S., Michel, S., Luhmann, C., Grundke, K. and Voit, B. (2008) Surface Functionalization of Silicone Rubber for Permanent Adhesion Improvement. Langmuir, 24, 12603-12611, http://dx.doi.org/10.1021/la801970s

[5] Jing, S.-Y. and Lee, H.-J. (2002) Chemical Bond Structure on Si-O-C Composite Films with a Low Dielectric Constant Deposited by Using Inductively Coupled Plasma Chemical Vapor Deposition. Journal of the Korean Physical Society, 41, 769-773.

[6] ASTM D 3163-01 (2001) Standard Test Method for Determining Strength of Adhesively Bonded Rigid Plastic LapShear Joints in Shear by Tension Loading. Annual Book of ASTM Standards, Vol. 15.06.

[7] Kinloch, A.J. (1987) Adhesion and Adhesives: Science and Technology. Chapman and Hall, London. http://dx.doi.org/10.1007/978-94-015-7764-9

[8] Charmeau, J.-Y., Chailly, M., Gilbert, V. and Béreaux, Y. (2008) Influence of Mold Surface Coatings in Injection Molding. Application to the Ejection Stage. International Journal of Material Forming, 1, 699-702. http://dx.doi.org/10.1007/s12289-008-0311-x 